African Research Review

An International Multidisciplinary Journal, Ethiopia

Vol. 7 (3), Serial No. 30, July, 2013:308-323

ISSN 1994-9057 (Print)

ISSN 2070--0083 (Online)

DOI: http://dx.doi.org/10.4314/afrrev.v7i3.22

\title{
Career Self Efficacy, Achievement Motivation and Organizational Commitment to Conflict Preventive Behaviour of Lecturers in Oyo Town
}

Adika, L. O. Ph.D. - Senior Lecturer, Department of Educational Psychology, School of Education, Emmanuel Alayande College of Education, P. M. B. 1010, Erelu, Oyo

E-mail: lawadika@yahoo.com

Phone: +2348033943982

Adesina, O. J. Ph.D. Department of Educational Psychology, School of Education, Emmanuel Alayande College of Education, P. M. B. 1010, Erelu, Oyo

E-mail:dradesina4u@yahoo.com

Phone: +2348033842629

$\&$

Rabiu, Oriyomi - Department of Educational Psychology, School of Education, Emmanuel Alayande College of Education, P. M. B. 1010, Erelu, Oyo

E-mail: oriyomi-rabiu@yahoo.com

Phone: +2348034284681 


\begin{abstract}
Career self efficacy, achievement motivation and organizational commitments are considered as predictors of lecturers' conflict preventive behaviours in tertiary institutions in Oyo town. 300 lecturers (149 male and 151 female) of the four tertiary institutions were randomly sampled. What is the relative contributions of each of the independent variables and their joint contribution to the dependent variable. Using regression analysis of coefficient of multiple regression $₫$ and multiple correlation square $\left(R^{2}\right)$ for data analysis and mean, standard deviation and intercorrelations to determine predictive values, it was found that these variables jointly contribute to conflict preventive behaviour but relatively all but achievement motivation contribute too. All stakeholders in lecturers' conflict behaviour have roles to play in developing preventive skills.
\end{abstract}

Key Words: Achievement, Achievement Motivation, Behaviour, Conflict Preventive Behaviour, Organizational Commitment.

\title{
Introduction
}

Employee's behaviors individually or collectively go a long way at affecting the total output of any organization. Employees put up different behaviours in different employees are basically informed by different beliefs, orientations, backgrounds, expectations and attitudes of these individuals.

Conflict preventive behaviour is an aspect of individual work attitude, thus it become important to consider some factors which may account for lecturer's conflict preventive behaviour such as self efficacy, motivation and goal achievement.

Self efficacy is people's beliefs about their capabilities to produce designated levels of performance that exercise influence over events that affects their lives. Self efficacy beliefs determine how people feel, think, motivate themselves and behave. A strong sense of efficacy enhances human accomplishment and personal well being. Efficacy determines individuals' approaches to tasks. While highly officiated people (people with high assurance in their capabilities) approach difficult tasks as challenges to be avoided lowly officiated people approaches the same as threats to be avoided. Career self efficacy helps to foster intrinsic interest, deep engrossments, setting challenging goals and maintenance of commitment to goal achievement in one's career. Career self efficacy refers to one's belief in one's capabilities to successfully engage in a specific career. Career self 
efficacy will help an employee to sustain and heighten effort in the face of failure and make guided recoveries and re-trials after initial failures or set back on an assignment in the career.

Career self efficacy may make an individual attribute failure to insufficient efforts or deficient knowledge and skills which he sees as acquirable. Such individuals approach tough career related situations with the assurance that they can exercise control over them, such efficacious approach produces personal accomplishments, reduce stress, and reduces possibilities of frustration and depressions.

Human courses of actions are initially charted out in thoughts. Hence, efficacy is capable of influencing the anticipatory scenario that they construct and rehearse e.g. high efficacy may generate success scenarios that provides positive guides and encouragements for higher performance while low efficacy may generate blurred expectation or no expectation at all. It requires a strong sense of efficacy to remain task oriented in the face of tough demands, failures and setbacks that have significant repercussions. When individuals are besetted with these taxing situations the clarity of their thoughts in relation to the goal achievement becomes very important; an individual's thought processes in such circumstances is a product of self efficacy.

Finally, career self efficacy contribute to motivation in certain ways, they determine the goals people set for themselves, how much efforts they expend, how long they persevere and their reactions to failures.

Motivation can be defined as the driving force behind all the actions of an individual. Adeyemo and Aremu (1999) describe motivation as the hypothetical construct or notion representing an inner sense capable of explaining motives, drives, needs or desires which energizes and directs human behaviour towards goal achievement. Motivation explains the 'whys' of human actions; it is the underlying reason behind the actions of individuals.

The term is a coinage from the Latin word "movere" which means "to move into action'. The term motivation can also be seen as motive action, which may be described as the motive for an action. In relating motivation to organizational psychology, Akinboye (2001) described motivation as "the need for sustainable approach to maintain enthusiastic commitment on a job from year to year from an employee". 
The influence of an individual's need and desires has strong impact on the direction of their behaviour. Motivation is base on the individual's emotion and achievement related goals. Different forms of motivation may include extrinsic, intrinsic, physiological and achievement motivation.

Achievement motivation is described as the need for success or the hunger for attainment of excellence. Achievement motivation may be satisfied through different means of different individuals and these individuals are driven to succeed for diverse reasons, both internal and external. Achievement motivation is based on reaching success and achieving all of our aspirations in life. Achievement goals can affect the way a person performs a task and represent a desire to show competence. Basic physiological motivational drive affects the individual employee's behaviour in a work setting. Our motive for achievement can range from biological needs to satisfying creative desires or realizing success in competitive ventures. Achievement motivation is important because it affects the behaviours, actions, thoughts and beliefs of an employee in a work setting. Although literatures and theories on achievement motivation abounds, these theories despite been developed by diverse scholars are very similar and collaborating rather than competing and disputing one another. Motivational researchers have sought and avowed achievement motivation by incorporating the two prominent theories, viz: the achievement motive approach and the achievement goal approach.

Achievement motive approach emphasizes the need for achievement and the fear of failure. These refers to the prominent motives that directs our behaviour toward positive outcomes while achievement goals are viewed as more solid cognitive representations point an individual towards a specific end. Achievement goals can be classified into: performance approach goal, performance avoidance goal and mastery goal. Achievement motives can be said to have distal influence while achievement goals can be said to have proximal influence on achievement relevant outcomes (Elliot and McGregor, 1999). Achievement motivation can be implicated by several factors such as: achievement motivation and information seeking; motivation and self worth and achievement motivation and intrinsic goals.

The management of people at work is an integral part of management process. To understand the critical importance of people in the organization is to recognize that human elements and the organization are synonymous. Well managed organizations usually sees an average worker as the roof 
source of quality and productivity and profit, such organizations do not look up to capital investment but to employees as the fundamental source and sustenance of improvement. Organizational effectiveness may be determined by the degree to which an organization achieve its goals. An effective organization will strive to achieve a high level of spirits of cooperation, job satisfaction and commitment among it employees, within the sphere of it influence. To get employee committed to their jobs in tertiary institutions there is a need for strong and effective motivation which may have impact on employees level of satisfaction at all cadre. Hence, organizational commitment should not be considered in isolation but in relationship with motivation and job satisfaction.

A similar definition of commitment emphasizes the importance of behaviour in creating it. Salancik (1977) conceives commitment as a state of being in which an individual becomes bound by his actions and it is these actions that sustains his activities and involvement. From this definition, it can be inferred that three features of behavior are important in binding individuals to act: visibility of acts, the extent to which the outcomes are irrevocable; and the degree of which the person undertakes the action voluntarily. To Salancik therefore, commitment can be increased and harnessed to obtain support for the organizational ends and interests through such things as participation in decision-making.

Guest (1991) concludes that high organizational commitment is associated with lower turnover and absence, but there is no clear link to performance. It is probably wise not to expect too much commitment as a means of making a direct and immediate impact on performance. It is not the same as motivation. Commitment is a broader concept and tends to withstand transitory aspects of an employee's job. It is possible to be dissatisfied with a particular feature of a job while retaining a reasonably high level of commitment to the organization as a whole. When creating a commitment strategy, Armstrong (1999) asserts that "it is difficult to deny that it is desirable for management to have defined strategic goals and values. And it is equally desirable from management point of view for employees to behave in a way that support those strategies and values". Creating commitment includes communication, education, training programmes and initiatives to increase involvement and ownership and the development of performance and reward management systems. 
There are many definitions of organizational commitment, but researchers agree that organizational commitment reflects a multidimensional psychological attachment of an individual to the organization. Organizational commitment has two basic dimensions: (a) it characterizes the employee's relationship with the organization, and (b) it has implication for the decision to continue or stop membership in the organization commitment may be either affective, continuance and normative organizational commitment.

Conflict is an essential ingredient in any society and there is conflict energy in every individual which may be geared either ways i.e. positively or negatively. Gearing conflict energy positively may lead to less stress, cohesive family, development, better informed populace, good government, vibrant political parties, but if expressed negatively may induce pain, death, violence, destruction and bad followership, divided society, poor infrastructures among other forms of hardships.

Goldstein (1993) emphasizes that conflict is a very complex phenomenon which means different things to many different people. It is sometimes described as competitive or aggressive behaviours. It is said to involve negative interpersonal perceptions and feelings. Conflict is described in terms of what might have caused it; such as scarce resources. Most times, it is defined in terms of its win or loss outcomes. But invariably these descriptions do not reach the core meaning of conflict. Rather, describe various manifestation of an underlying construct. Hammed (2006) opined that conflict is a basic psychological mechanism that centres around incompatible goals; that conflict exists whenever one set of goals, needs or interest disagree with another set.

Conflict is the interaction of interdependent people who perceive incompatible goals and interference from each other in achieving those goals. This definition provides a much clearer focus on what conflict is all about. It departs from those that view conflict as disagreement, competition. Conflict is almost always caused by unlike points of view. This is because we have not learned exactly alike and because, we therefore, see and value things differently, we vary in our beliefs as to what things are or should be. Also because conflict large or small is inevitable, the extreme result at either end is a situation that is undesirably abrasive or dialogue that is creatively productive or the presence of incompatible goals.

The list of positive and creative values inherent in conflict is equally long as: it opens up an issue in a confronting manner, it develops clarification of an 
issue, it increases involvement, it improves problem-solving quality, it provides more spontaneity in communication, it strengthens a relationship when creatively resolved, it can increase productivity. We may therefore avoid the problem of confusing conflict with the methods of waging and resolving it; and we recognize that its outcomes can be negative or positive. It should be noted that certain amount of tension and disagreement is normal and desirable in every work setting. As a matter of fact, a complete absence would be boring, unchallenging and unbelievable at the work place.

It is important to note that conflict prevention is not the same as conflict avoidance. Conflict prevention involves the elimination of unnecessary conflict that occurs in the work place, yet it is not just avoiding conflict or hoping it will go away on its own or just sweeping it under the carpet. Conflict prevention approach may include the following: (a) the logical conflict management approach such as: avoidance, collaboration and compromise; (b) emotional models.

Conflict prevention in educational set-ups is linked to democracy and citizenship developing a peaceful work environment. Cooperative work force, cultural tolerance, prejudice reduction, social justice, violence prevention and intervention, critical thinking and problem solving and value base management are very important to conflict prevention.

\section{Statement of the Problem}

Everyday diverse individuals of diverse backgrounds, personalities, values and goals interact together in their place of work i.e. tertiary institutions. Their uniqueness and diversity is bond to create conflicts which may lead to stress, fatigue and strike actions. Differences in the opinions of the management, lecturers and students, may lead to conflict situations. Work overload, demand for higher pay, downsizing, retrenchments and other policies may lead to conflict situations in our tertiary institutions. Hence, like any other human settings conflict becomes inevitable and the need to study the conflict behaviours of our tertiary institutions lecturers becomes necessary.

\section{Purpose of the Study}

Although researches and publications on organizational conflicts now abound majority of these are focused on conflict management and resolutions. Yet there are other very important areas of conflict that require attentions such as generation, sustenance, avoidance and prevention. Hence, this research work 
becomes highly imperative at this time as a way of exploring possible conflict preventive measures and approaches that could be adopted by tertiary institution.

The study also becomes purposeful in its attempt to determine the effects of it independent variables i.e. career self efficacy, achievement motivation and organizational commitment as predictors of individual lecturers conflict preventive behaviours i.e. the dependent variable.

\section{Significance of the Study}

The findings of this study will be of major interest to various groups and stakeholders of conflict groups of conflict attitudes of tertiary institution lecturers hence the relevance of the study is multi-dimensional.

The study will afford the subjects i.e. tertiary institution lecturers the opportunity to express their individual opinions about self on career efficacy, achievement motivations and organizational commitment thus reinforcing each persons uniqueness.

The study will also afford managements of various tertiary institutions an insight into possible conflict preventive measures that could be effective among tertiary institution lecturers.

The study will be useful in attracting the interests of organizational conflict researchers to other aspects of conflict away from the very popular areas of management and resolution.

The study will also be a significant contribution to the academics especially the field of organizational psychology. The study may also lead to other researches since research is cyclic and open-ended i.e. the search for explanation of a problem may lead to identification of other related problems, hence this work will serve as a reference point to researches of similar topics in the future.

\section{Research Questions}

From the foregoing, the following research questions were formulated.

1) What is the relative contribution of each of these independent variables i.e. (a) career self-efficacy, (b) achievement motivation, (c) organizational commitment on the dependent variable i.e. conflict preventive behaviour? 
Career Self Efficacy, Achievement Motivation and Organisational Commitment ...

2) What is the joint contribution of these variables to conflict preventive behaviours of lecturers?

\section{Methodology}

\section{Research Design}

This research is a proximal research because deductions from it findings may be limited to lecturers in Oyo and its environs. It is a descriptive survey that observes the behaviours of its subjects as reported by the respondents to the administered instrument.

\section{Population and Sample}

The population of this research includes every teacher in the four tertiary institutions in Oyo town, viz:

1) Emmanuel Alayande College of Education, Erelu, Oyo

2) Federal College of Education (Special), Akinmorin, Oyo

3) Federal School of Surveying, Oyo

4) Ajayi Crowther University, Oyo

From these teachers who number about 1,500. 300 were randomly selected as samples on whom the instrument was administered. The simple random sampling technique was employed. The instrument was administered on any of the member of the population that was available as at the time of visits of the researcher to each of these schools.

At the end of the day the sample distribution is as follows:

1) Emmanuel Alayande College of Education, Erelu, Oyo

2) Federal College of Education (Special), Akinmorin, Oyo

$=125$

3) Federal School of Surveying, Oyo

4) Ajayi Crowther University, Oyo 


\section{Instrumentation}

This research work made use of instrument titled "lecturers conflict preventive behaviour inventory". The inventory is a four sectional instrument; each section is an adaptation of parts of an earlier validated instrument relevant to each of the variables.

Section A which tested respondents' career self efficacy is an adaptation of Betz, Klein and Taylor (1996)'s Career Decision Self Efficacy Scale (CDMSE). The CDMSE is a 25 - item measure. Response options range from no confidence at all (1 point) to complete confidence ( 5 points). Higher scores reflect higher career decision making self-efficacy. Estimates of internal consistency ranged from .73 to .83 for the subscales and .94 for the total score (Betz, et al, 1996).

Section B which tested respondents' achievement motivation is an adaptation of Hammed and Aremu's Ibadan Multi-Dynamic Inventories of Achievement Motivation (2002). The inventory is a 20 item inventory titled General Achievement Motivation Scale which graded respondents along a continuum of $1-4$ i.e. very unlike me to very like me.

Section C which tested respondents organizational commitment is an adaptation of Modway Steers and Porter (1979)'s Organizational Commitment Questionnaire (OCQ). The OCQ which required participants to indicate the degree to which they agreed with the given statements on a 7 point scale which ranged from 1 (strongly disagree) to 7 (strong agree). Cronbach's alpha for the OCQ with the current data revealed a very satisfactory level of internal consistency (0.93). The scale employs a threedimensional conceptualization of commitment involving affective, continuance and normative commitment. However, as Modway, Steers and Porter (1979) themselves point out, the items on the scale are relatively homogenous with respect to the underlying construct they measure, that of attitudinal commitment, which involves a desire to remain in the organization and the acceptance of organizational values (Meyer and Allen, 1991).

Section D which tested respondents' conflicts managerial skills is an adaptation of Goldstein's Conflict Management Inventory (CMI). The CMI is a 15-item standardized measure designed to discover conflict preventive strategies by individuals. This tool has been developed as a standardized personality instrument. Participants are asked to rate the degree to which a 
statement reflects their approach to conflict resolution, using a scale from 1 (strongly disagree) to 7 (strongly agree).

\section{Procedure for Data Collection}

The researcher had to pay several visits to each of institutions over a period of about 3 weeks. The researcher ensured a personal contact with each of the respondents, while some of them, required little or no prompting and explanations, others had to be prompted and given detailed explanations.

Some of the respondents responded to the instrument and returned it to the researcher on the spot others had to ask the researcher to come back for the instrument. In all, the researcher produced 360 copies of the instrument and was able to retrieve 300 .

\section{Data Analysis}

To determine the 3 independent variables as predictors of the dependent variable the researcher made use of regression analysis taking into consideration co-efficient of multiple regression (R) and multiple correlation square $\left(\mathrm{R}^{2}\right)$. To determine the Betas of variables the researcher made use of standardized and unstandardised co-efficient. To determine the predictive values of each of the variables the researcher made use of mean, standard deviation and intercorrelations among the variables.

\section{Results}

\section{Research Question I}

To what extent will career self efficacy, achievement motivation and organization commitment jointly predict conflict preventive behaviour of tertiary institutions lecturers?

Table 1: Summary of regression analysis career self efficacy achievement motivation and organization commitment on conflict preventive behavior

\begin{tabular}{|c|l|l|c|c|c|c|}
\hline & & Source & DF & SS & MS & F-Ratio \\
\hline 1 & R & Regression & 3 & 5278.832 & 1759 & 5.10 \\
& 0.351 & & & & & \\
\hline 2 & $\begin{array}{l}\mathrm{R}^{2} \\
\end{array}$ & Residual & 292 & 517249.688 & 432.483 & \\
\hline 3 & $\begin{array}{l}\text { S.E } \\
\text { 3.37 }\end{array}$ & Total & 299 & 522528.512 & & \\
\hline
\end{tabular}


Table 1 show that the combination of the independent variable (career self efficacy, achievement motivation and organizational commitment) in predicting conflict preventive among the tertiary institutions lecturers yielded a coefficient of multiple regression ( $\mathrm{R}$ ) of .351 , multiple correlation square (R) of .301. The result show that $30.1 \%$ of the independent variable (career self efficacy achievement motivation and organization commitment). The table also indicates that the analysis of variance of the multiple regression data gave an F-ration of 5.10 significant at .50 level

\section{Research question II}

To what extent will each of the independent variance (i.e career self efficacy achievement motivation and organization commitment).relatively predict job satisfaction among the university lecturers?

Table 2: The betas of variable to the prediction of job satisfaction

\begin{tabular}{|c|c|c|c|c|c|}
\hline & 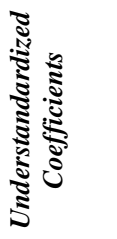 & & 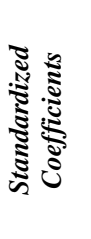 & $\omega$ & : \\
\hline & $\mathrm{B}$ & Std. Error & Beta & & \\
\hline (Constant) & 35.121 & 3.915 & & 8.92 & 0.000 \\
\hline Career self efficacy & .124 & .037 & .288 & 4.31 & $<0.05$ \\
\hline Achievement motivation & .144 & .044 & .022 & 1.20 & NS \\
\hline Organization commitment & .110 & 0.33 & .205 & 3.16 & $<0.05$ \\
\hline
\end{tabular}

Table 2 indicate for each independent variable, the standard error under standardized regression (beta), the T-ration and level at which the T-ration is significant. From the table, it can be seen that T-ration association with career efficacy achievement motivation and organization commitment were significant at 0.05 level except achievement motivation. Furthermore, the relation contribution of each of the independent variable to the prediction of conflict prevention behaviour among the lecturers is indicate by the T-ration 
attached to each independent variable with career efficacy having the highest contribution, followed by organization commitment achievement motivation could not predict prevention behaviour among the lecturers.

Table 3: Mean standard deviation and inter-correlation among predictor and organization commitment of lecture $(\mathrm{N}=300)$

\begin{tabular}{|c|l|c|c|c|c|}
\hline & \multicolumn{1}{|c|}{ Variables } & \multicolumn{1}{c|}{$\mathbf{2}$} & $\mathbf{2}$ & $\mathbf{3}$ & \\
\hline 1 & $\begin{array}{l}\text { Conflict preventive } \\
\text { behaviour }\end{array}$ & 1.000 & & & \\
\hline 2 & Career self efficacy & 0.211 & 1.000 & & \\
\hline 3 & $\begin{array}{l}\text { Achievement } \\
\text { motivation }\end{array}$ & 0.028 & 0.115 & 1.000 & \\
\hline 4 & $\begin{array}{l}\text { Organizational } \\
\text { commitment }\end{array}$ & 0.248 & 0.010 & $.238^{*}$ & 1.000 \\
\hline 5 & Mean & 1.5800 & 1.6900 & 27.5400 & 56.25 \\
\hline 6 & Stand deviation & 0.4948 & 0.5637 & 17.3094 & 12.82 \\
\hline
\end{tabular}

Correlation matrix mean and standard deviation of the measured variable are reported in table 3 . The result showed that self efficacy and organization commitment were significantly correlated with conflict preventive behaviour ( $\mathrm{r}=.211$ and $.243, \mathrm{p}<0.05$ respectively). This is an indication of strong relationship. However, achievement motivation does not positively correlate with preventive behaviour.

\section{Discussion of findings}

The results are discussed on the bases of the research questions. By the results presented in Table 1, the three independent variables viz career self efficacy, achievement motivation and organizational commitments as predictors of conflict preventive behaviours produce a co-efficient of multiple regression $(\mathrm{R})$ of .351 . The analysis of variance of multiple regression data gave a $\mathrm{F}$ - ratio of 5.10 which is significant at .05 level, hence the independent variables $30.1 \%$ of the lecturers conflict preventive behaviours. 
The research question "what is the joint contribution of these variables to conflict preventive behaviours of lecturers" was answered by these findings as the dependent variables can be greatly implicated by of these independent variables.

The result presented in Table 3 shows the correlation matrix and standard deviation of these 3 variables. Thus indicating a high correlation between career self efficacy and organizational commitment with conflict preventive behaviours, thereby showing a strong relationship between these two independent variables and the dependent variable, achievement motivation does not positively correlate with conflict preventive behaviour indicating a very weak relationship and implication between achievement motivation and conflict preventive behaviours.

To reinforce the result in Table 3, Table 2 highlights the standard error, unstandardized regression co-efficient (B), the standardized co-efficient (Beta), the T-ratio and level of significance of the T-ratio. The magnitude of these $\mathrm{T}$-ratios are indications of their contributions to the dependent variable. Career self efficacy and organizational commitment were significant at 0.05 level while achievement motivation is insignificant.

Hence to answer the research question "what are relative contributions of each of these independent variable on the conflict bahaviours of lectures?" the finding have shown that career self efficacy has the highest contribution, followed by organization commitment and achievement motivation has least (insignificant) contribution on the dependent variable

\section{Implications of findings}

The finding have to establish fact that lecture don't just develop conflict preventive behaviours. These behaviours are informed by certain factors and such factors may be very diverse. It is important for manager to correctly identify this factor and position themselves and these lecture to maximize their knowledge of the predictive capabilities of these various factors.

The research would like to suggest that future relevant studies be encouraged to probe for an investigation other possible of conflict preventive behaviour such as job satisfaction, lecture, family and region backgrounds, among others. Again, more time frames should be allowed for such works. 


\section{Recommendation}

(1) Various stakeholders in the issue of lecturers' conflict preventive behaviour have roles to pay to improve the levels of conflict management skill of our tertiary institution lecturers.

(2) The financiers of tertiary institutions such as governments, corporate bodies and individuals, should make available sufficient funds for the purpose of training and retraining of institution management and lecturers on a regular basis.

(3) Institution management should encourage lecturers to under go regular conflict management courses and seminars, this they can achieve by setting the examples in that direction. They should also be prepared to adopt preventive rather than curative measures in terms of conflict, and if conflict must ensued it must be resolved to bring about a positive outcome.

(4) Lecturers generally should appreciate the fact that issue base conflict are more beneficial than person base conflict, hence, if they must conflict should be base on issues. They should also avail themselves the opportunities of learning more about conflict and peace management skills.

(5) The academic can impact on the present and future generations of lecturers as it relate to conflict issues through their continuous research and writings on this very critical issue. 


\section{References}

Adeyemo, D. A. \& Aremu, A. O. (1999). Career Commitment among Secondary School Teacher in Oyo State, Nigeria. The Role of Biographical Mediators. Nigerian Journal of Applied Psychology, 5(2),184- 194.

Akinboye, J.O. (2001). Executive Behaviour Battery. Ibadan: Stirling-Horden Publishers.

Armstrong, M. (1999). Human Resources Management Practice. London: Kogan Page.

Betz, Klein \& Taylor (1996). Career Decision Self Efficacy Scale.

Elliot and McGregor (1999). "Career Oriented Versus Team Oriented Commitment and Behaviour at Work". Journal of Applied Psychology, 83 (3), 717-730.

Goldstein (1993). Conflict Management Inventory.

Guest, E.A. (1991). Human Resources Management. London: McGraw-Hill.

Hammed, and Aremu, A. O. (2002). Ibadan Multi-Dynamic Inventories of Achievement Motivation.

Meyer, J.P., \& Allen, N.J (1997). Commitment in the Workplace: Theory, Research and Application. Thousand oaks, CA: Sage.

Modway, Steers and Poter (1979). Organization Commitment Questionnaire.

Salancik, G.R. (1977). "Commitment and the Control or Organization Behaviour and Belief". In B. Staw and G. Salancik (Ed), New Direction in Organizational Behaviour. Chicago: St. Clair Press, 159. 